\title{
Absence of Nuclear p16 Is a Diagnostic and Independent Prognostic Biomarker in Squamous Cell Carcinoma of the Cervix
}

\author{
Saioa Mendaza ${ }^{1}$, Joaquín Fernández-Irigoyen ${ }^{2}$, Enrique Santamaría ${ }^{2}{ }^{\oplus}$, Tamara Zudaire ${ }^{3}$, \\ Rosa Guarch ${ }^{3}$, David Guerrero-Setas ${ }^{1,3}$, August Vidal ${ }^{4}$ (D) José Santos-Salas ${ }^{5}$ (D) \\ Xavier Matias-Guiu 4,6, Karina Ausín ${ }^{2}$, María José Díaz de Cerio ${ }^{3}$ and \\ Esperanza Martín-Sánchez ${ }^{1, *}$ \\ 1 Molecular Pathology of Cancer Group, Navarrabiomed, Complejo Hospitalario de Navarra (CHN), \\ Universidad Pública de Navarra (UPNA), Instituto de Investigación Sanitaria de Navarra (IdiSNA), \\ Irunlarrea 3, 31008 Pamplona, Spain \\ 2 Proteored-ISCIII, Proteomics Unit, Navarrabiomed, Complejo Hospitalario de Navarra (CHN), Universidad \\ Pública de Navarra (UPNA), Instituto de Investigación Sanitaria de Navarra (IdiSNA), Irunlarrea 3, \\ 31008 Pamplona, Spain \\ 3 Department of Pathology, Complejo Hospitalario de Navarra (CHN), Irunlarrea 3, 31008 Pamplona, Spain \\ 4 Department of Pathology, Hospital Universitari de Bellvitge, IDIBELL, Carrer de la Feixa Llarga, \\ 08907 L'Hospitalet de Llobregat, Spain \\ 5 Department of Pathology, Complejo Asistencial Universitario, Altos de Nava, 24071 León, Spain \\ 6 Department of Pathology and Molecular Genetics, Hospital Universitari Arnau de Vilanova, \\ University of Lleida, Alcalde Rovira Roure 80, 25198 Lleida, Spain \\ * Correspondence: espemartinsanchez@gmail.com
}

Received: 7 February 2020; Accepted: 18 March 2020; Published: 19 March 2020

check for updates

\begin{abstract}
The tumor-suppressor protein p16 is paradoxically overexpressed in cervical cancer (CC). Despite its potential as a biomarker, its clinical value and the reasons for its failure in tumor suppression remain unclear. Our purpose was to determine p16 clinical and biological significance in CC. p16 expression pattern was examined by immunohistochemistry in 78 CC cases (high-grade squamous intraepithelial lesions (HSILs) and squamous cell carcinomas of the cervix -SCCCs). CC cell proliferation and invasion were monitored by real-time cell analysis and Transwell ${ }^{\circledR}$ invasion assay, respectively. Cytoplasmic p16 interactors were identified from immunoprecipitated extracts by liquid chromatography-tandem mass spectrometry, and colocalization was confirmed by double-immunofluorescence. We observed that SCCCs showed significantly more cytoplasmic than nuclear p16 expression than HSILs. Importantly, nuclear p16 absence significantly predicted poor outcome in SCCC patients irrespective of other clinical parameters. Moreover, we demonstrated that cytoplasmic p16 interacted with CDK4 and other unreported proteins, such as BANF1, AKAP8 and AGTRAP, which could sequester p16 to avoid nuclear translocation, and then, impair its anti-tumor function. Our results suggest that the absence of nuclear p16 could be a diagnostic biomarker between HSIL and SCCC, and an independent prognostic biomarker in SCCC; and explain why p16 overexpression fails to stop CC growth.
\end{abstract}

Keywords: cytoplasmic p16; nuclear p16; subcellular location; predictive biomarker; squamous cell carcinoma of the cervix; high-grade squamous intraepithelial lesion; cervical cancer

\section{Introduction}

Squamous cell carcinoma of the cervix (SCCC) accounts for $70-80 \%$ of all cervical cancer (CC) cases, which is the fourth most frequent cancer type in women worldwide [1], with a 5-year survival 
of $57-67 \%$ in Europe [2]. SCCC pathogenesis is a slow multi-stage process: when a high-risk human papillomavirus (HR-HPV) infection—present in $99.7 \%$ of cases [2,3]—persists in dividing cells, these can originate a high-grade squamous intraepithelial lesion (HSIL); if, additionally, some molecular alterations occur, tumor cells extend beyond the basement membrane of the epithelium, and then an invasive carcinoma appears [3,4]. Unfortunately, early SCCC is often asymptomatic and detected at an advanced stage when treatments are ineffective. Developments in early diagnosis are therefore much needed [1]. Currently, the standard method for SCCC diagnosis has many limitations because it is mainly based on subjective interpretation of histological changes in cervical tissue [2,4-6]. Intriguingly, as CC development seems to be a continuous process, it is quite difficult to morphologically distinguish an HSIL which has begun to invade and an SCCC which has just penetrated the basement membrane. However, these apparently similar tumors display very different clinical behaviors. Women with HSIL are treated with surgery that is usually successful, with more than $85 \%$ of patients being cured [7]; those with SCCC receive surgery plus chemoradiotherapy, but unfortunately, half of them die from the disease [2]. An accurate diagnosis is therefore crucial for the successful clinical management of these patients.

Recently, an HPV DNA test has been introduced as a screening tool; this has proved to be much more sensitive than traditional methods [2], indicating that molecular biomarkers are very informative and of great utility. Indeed, they are objective, quantitative and easily reproducible in all hospitals and laboratories, for many tumor types [8-10]. However, to date, no molecular panel has been available for SCCC, in contrast to other malignancies, such as breast [8,11], lung [12] and colorectal [13] cancers, so there is an urgent need for molecular biomarkers that will enable early diagnosis, prognosis and targeted therapy for SCCC [14]. A better understanding of the molecular mechanisms leading to SCCC could help us develop better clinical strategies to improve patients' likelihood of survival. In fact, the European Society of Medical Oncology has recommended that more research be undertaken to identify molecular biomarkers in CC [2].

The cyclin-dependent kinase inhibitor $2 \mathrm{~A}$ protein, also called p16, is a well-known tumor-suppressor protein which is down-regulated in many tumors, and is involved in regulating cell cycle, senescence, apoptosis, cell invasion and angiogenesis $[3,5,15]$. In spite of these well-recognized tumor-suppressor properties, p16 expression paradoxically increases with the severity of the cervical lesion $[3,5,14,16]$, and has been then proposed as a useful marker for identifying such lesions [5,17-20]. In fact, its ancillary use in cervical cytology has improved the accuracy of histological diagnosis $[5,21]$, mainly in premalignant lesions [4]. However, the specificity of p16 has been insufficiently studied in SCCC [18], and its prognostic value remains controversial [3,5,14].

As there is a lack of consensus and clear guidelines regarding the use of $\mathrm{p} 16$ expression in routine clinical management of SCCC $[2,5,19]$, we aimed to shed some light on the clinical utility and biological significance of p16 overexpression during SCCC progression.

\section{Results}

\subsection{Expression Pattern and Clinical Relevance of $p 16$ in SCCC Patients}

Global p16 expression was examined in our series of 29 HSILs and 49 SCCCs, taking into account the criteria which are routinely used in the clinical practice. We observed that SCCC tumors had a significantly higher level of p16 expression than did HSILs $(p<0.001)$ (Figure 1A and Table 1). No statistical association was found between global p16 expression and pathological variables (data not shown). Interestingly, significant associations between a high level of global p16 expression and good prognosis and outcome were found in SCCC patients (Figure 1B), independent of other clinical parameters crucial in SCCC prognosis, such as age, stage and vascular invasion (Figure 1C and Figure S1). Indeed, Cox analyses showed that strong expression of $\mathrm{p} 16$ had a protective effect against relapse and death (hazard ratios 0.079 and 0.031 for progression-free survival (PFS) and overall survival (OS), respectively) (Figure 1C). These results contribute to the paradox of p16 overexpression 
in SCCC, since a tumor-suppressor protein which significantly adds to a good outcome is overall overexpressed in this aggressive cancer type.

A

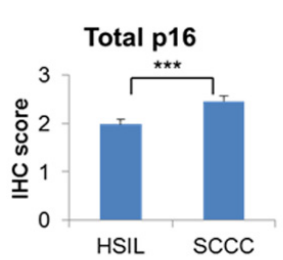

B

\begin{tabular}{lcc}
\hline Variable & $p$-value & Hazard ratio $(95 \% \mathrm{Cl})$ \\
\hline Age $(\geq 45$ vs $<45)$ & 0.223 & $2.758(0.539-14.124)$ \\
Stage $(3-4$ vs $1-2)$ & 0.001 & $15.606(3.099-78.586)$ \\
Vascular invasion $(\mathrm{N}$ vs $\mathrm{Y})$ & 0.789 & $0.802(0.159-4.046)$ \\
p16 expression $(2-3$ vs $0-1)$ & 0.005 & $0.079(0.013-0.473)$
\end{tabular}

HSIL

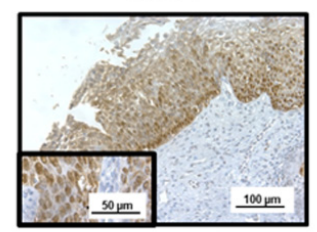

$\operatorname{sccC}$
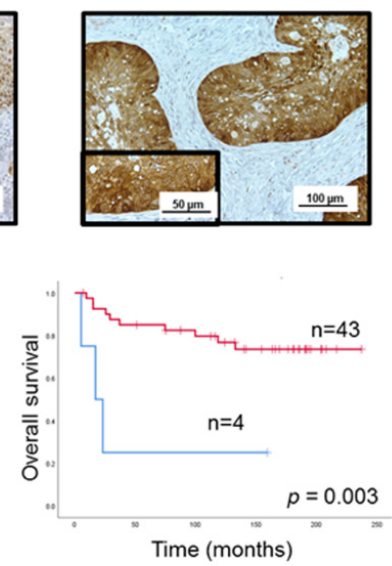

\begin{tabular}{lcc}
\hline Variable & $p$-value & Hazard ratio $(95 \% \mathrm{Cl})$ \\
\hline Age $(\geq 45$ vs $<45)$ & 0.312 & $3.180(0.337-29.958)$ \\
Stage $(3-4$ vs $1-2)$ & 0.003 & $26.772(3.094-231.696)$ \\
Vascular invasion $(\mathrm{N}$ vs $\mathrm{Y})$ & 0.148 & $0.221(0.028-1.712)$ \\
p16 expression $(2-3$ vs $0-1)$ & 0.003 & $0.031(0.003-0.298)$
\end{tabular}

Figure 1. Global p16 expression in cervical tumors. (A) Immunohistochemical expression of p16 was examined in a series of 29 high-grade squamous intraepithelial lesions (HSILs) and 49 squamous cell carcinomas of the cervix (SCCCs) $\left.{ }^{* * *} p<0.001\right)$. Representative images are shown at $200 \times$ magnification, and details are highlighted at 400x. (B) Association between global p16 expression and progression-free survival (PFS) and overall survival (OS) in SCCC patients. (C) Multivariate analysis showing the independent association between p16 expression and PFS (left) or OS (right), regardless of vascular invasion, stage and age of SCCC patients. (CI, confidence interval).

Table 1. Distribution of p16 expression and subcellular location in our series of 78 cervical tumors. Number and percentage of high-grade squamous intraepithelial lesions (HSILs) $(n=29)$ and squamous cell carcinomas of the cervix (SCCCs) $(n=49)$ patients with negative (0), weak (1), moderate (2) and strong (3) immunohistochemical expression of global, nuclear and cytoplasmic p16 protein levels. The cytoplasmic/nuclear p16 ratio was calculated by dividing cytoplasmic by nuclear p16 immunohistochemical score.

\begin{tabular}{ccc}
\hline Global p16 & No. of HSILs & No. of SCCCs \\
\hline 0 & $1(3 \%)$ & $2(4 \%)$ \\
1 & $2(7 \%)$ & $3(6 \%)$ \\
2 & $17(59 \%)$ & $6(12 \%)$ \\
3 & $9(31 \%)$ & $38(78 \%)$ \\
\hline Nuclear p16 & & \\
0 & $1(3 \%)$ & $3(6 \%)$ \\
1 & $4(14 \%)$ & $3(6 \%)$ \\
2 & $10(34 \%)$ & $16(33 \%)$ \\
3 & $14(48 \%)$ & $27(55 \%)$ \\
\hline Cytoplasmic p16 & & \\
0 & $1(3 \%)$ & $3(6 \%)$ \\
1 & $8(28 \%)$ & $3(6 \%)$ \\
2 & $19(66 \%)$ & $8(16 \%)$ \\
3 & $1(3 \%)$ & $35(71 \%)$ \\
\hline Cyt/nuc p16 ratio & & \\
$<1$ & $17(59 \%)$ & $6(12 \%)$ \\
$=1$ & $8(26 \%)$ & $21(43 \%)$ \\
$>1$ & $4(14 \%)$ & $22(45 \%)$ \\
\hline
\end{tabular}


In order to shed some light on this controversy, we focused on p16 subcellular location, and observed that SCCC tumors showed stronger cytoplasmic than nuclear staining than the HSIL samples, regardless of the global expression of the protein (Figure 2A and Table 1). Indeed, SCCC samples displayed a significantly higher cytoplasmic/nuclear p16 ratio than HSIL $(p<0.001)$. This finding suggests that not only p16 expression, but also its subcellular location, could be diagnostic biomarkers which can distinguish between HSIL and SCCC.

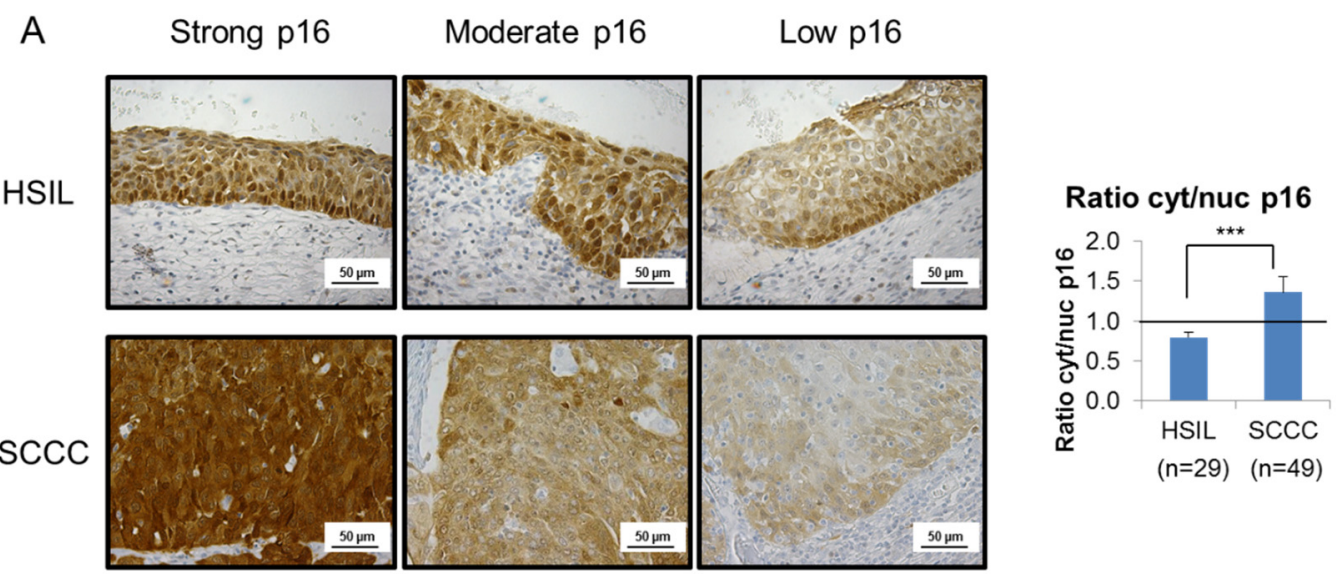

B

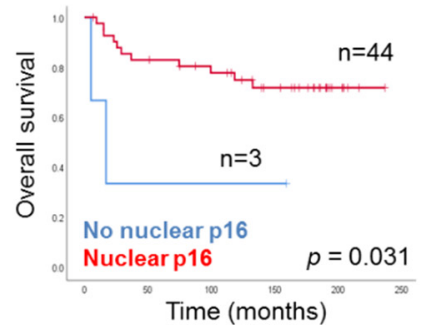

C

\begin{tabular}{lcc}
\hline Variable & $p$-value & Hazard ratio $(95 \% \mathrm{Cl})$ \\
\hline Age $(\geq 45$ vs $<45)$ & 0.147 & $6.871(0.508-92.869)$ \\
Stage $(3-4$ vs 1-2) & 0.001 & $52.401(4.778-574.731)$ \\
Vascular invasion $(\mathrm{N}$ vs $\mathrm{Y})$ & 0.129 & $0.253(0.043-1.491)$ \\
Nuc p16 expression (N vs $\mathrm{Y})$ & $\mathbf{0 . 0 0 2}$ & $\mathbf{2 3 2 . 1 2 8 ( 7 . 8 7 5 - 6 8 4 2 . 4 1 0 )}$
\end{tabular}

Figure 2. Subcellular location of p16 in cervical tumors. (A) Representative images of p16 staining in 3 high-grade intraepithelial lesions (HSILs) and 3 squamous carcinomas of the cervix (SCCCs) at 400x magnification showing that SCCC samples $(n=49)$ showed stronger cytoplasmic than nuclear p16 expression than HSIL $(n=29)$, regardless of the degree of global p16 staining (strong, moderate or low). Note p16 negativity in the nuclei of the low p16-expressing SCCC sample. The ratio cytoplasmic to nuclear (cyt/nuc) p16 expression was calculated by dividing p16 immunohistochemical score in each subcellular compartment. The horizontal line in the histogram shows equal amounts of cytoplasmic and nuclear p16 (ratio cyt/nuc p16 =1) $\left(^{* * *} p<0.001\right)$. (B) Association between $\mathrm{p} 16$ subcellular location and overall survival (OS) in SCCC patients. (C) Multivariate analysis revealed an independent association between p16 subcellular location and OS, regardless of vascular invasion, stage and age of SCCC patients. (CI, confidence interval).

Furthermore, although no significant association was found between nuclear or cytoplasmic p16 expression and pathological variables (data not shown), the absence of nuclear p16, observed in only $6 \%$ of SCCC patients though (Table 1$)$, was significantly associated with a very poor outcome $(p=$ 0.031 ) (Figure $2 \mathrm{~B}$ and Table S1). Moreover, this association was significantly independent of clinical parameters like age, stage or vascular invasion $(p=0.002)$; and we found that the lack of nuclear p16 significantly increased the risk of death by more than 200-fold (Figure 2C).

These findings indicate that although p16 is globally overexpressed in SCCC, it is not mainly located in the nucleus, where it could exert its tumor-suppressor functions. Therefore, these results could explain the p16 paradox in SCCC. 


\section{2. p16 Subcellular Location in SCCC Cell Lines}

p16 expression pattern was also interrogated in SCCC cell lines. Western blot (Figure 3A) and immunofluorescence (Figure 3B) revealed that C-33A cells expressed p16 in both the nucleus and the cytoplasm, while SiHa cells only expressed it in the cytoplasm. Similar to what we observed in SCCC tumors, this differential subcellular location could affect cell aggressiveness, as SiHa had greater proliferative (Figure 3C) and invasive (Figure 3D) properties than did C-33A. These abilities were also examined in the HeLa cell line (Figure S2), which was derived from a cervical adenocarcinoma, with nearly identical clinical features to SCCC [22]. Interestingly, we found a very similar pattern of p16 expression and growth and invasive capacities in HeLa and SiHa cells, indicating that the absence of nuclear location of $\mathrm{p} 16$ is related to CC aggressiveness.

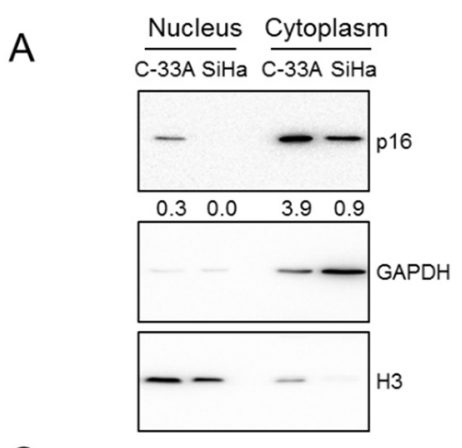

C

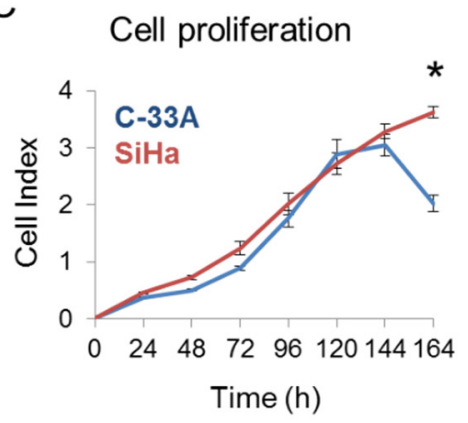

B

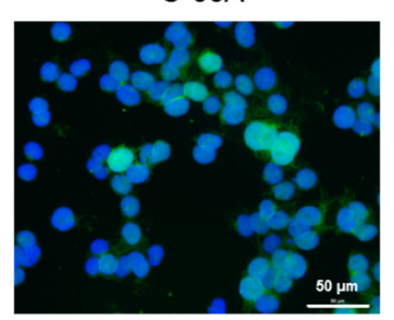

D
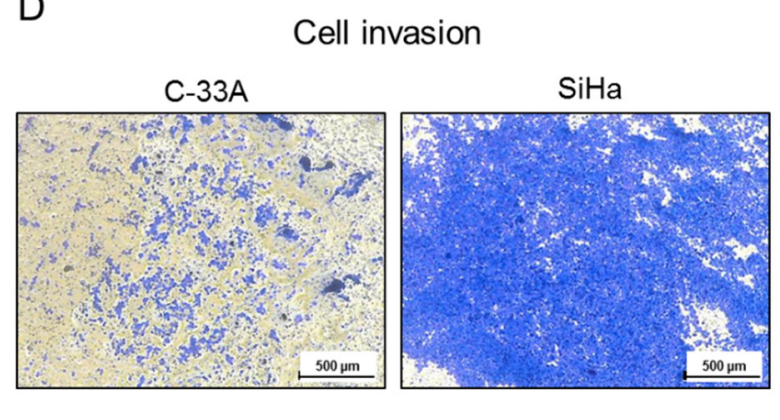

Figure 3. p16 subcellular location in SCCC cell lines. (A) Nuclear and cytoplasmic protein fractions of C-33A and SiHa were separately subjected to western blot to check p16 expression. GAPDH and Histone $\mathrm{H} 3$ were used as loading controls of each subcellular fraction. Numbers indicate the ratio of p16 signal relative to that in the loading control, measured by densitometry. (B) p16 expression was examined by immunofluorescence in $\mathrm{C}-33 \mathrm{~A}$ and $\mathrm{SiH}$ a cells. Images were acquired at $400 \times$ magnification. (C) Cell proliferation of C-33A and $\mathrm{SiHa}$ cell lines was measured by real-time cell analysis for 7 days $\left({ }^{*} p<0.05\right)$. (D) Cell invasion of C-33A and SiHa cell lines was examined by their ability to penetrate a Matrigel ${ }^{\circledR}$ layer for 3 days. Images were acquired at $50 \times$ magnification.

\subsection{Cytoplasmic $p 16$ Interactome in SCCC}

To understand why p16 is mainly confined to the cytoplasm in aggressive SCCC tumors, we hypothesized that it could be sequestered by other proteins to form large macromolecular complexes in order to avoid nuclear translocation, as has been described in other tumor types [15]. To test this hypothesis, we first examined the conformation of native p16 by western blot under non-denaturing conditions. We observed a band in $\mathrm{SiHa}$, but not in $\mathrm{C}-33 \mathrm{~A}$, which may indicate a differential 3D conformation of native p16 (Figure 4A). This finding suggested that p16 could actually be bound to other proteins that sequester it in the cytoplasm. Therefore, cytoplasmic p16 was immunoprecipitated from SiHa cells, which lacked nuclear p16 (Figure 3A). Figure 4B shows immunoprecipitation efficiency regarding the pull-down of p16 and its interactors, as one of the well-known proteins that interacts with p16, the cyclin-dependent kinase 4 (CDK4) [15], was also detected in our immunoprecipitated extract (Figure 4B). To be confident in the identification of 
p16 interactors, those extracts were digested by taking a dual approach-in-gel and in-solution digestion-and then subjected to liquid chromatography-tandem mass spectrometry (LC-MS/MS) (Table S2). Data mining of LC-MS/MS-generated proteomic data revealed that 16 proteins were simultaneously identified in both extracts pulled down with the anti-p16 antibody, but not with IgG (Table 2). They were proposed to be at least a part of the cytoplasmic p16 interactome in $\mathrm{SiHa}$ cells with a false-discovery rate $(\mathrm{FDR})<0.01$. It is worth mentioning that no protein from HPV was found to be bound to cytoplasmic p16. Importantly, we observed that the vast majority of those human interacting proteins had not been previously reported in the BioGRID interaction repository, which currently contains 229 interactors for p16 (January 2020). The only two proteins found to be common to the BioGRID list and the immunoprecipitated extracts digested in-gel and in-solution were CDK4 and C1QBP (Figure S3). Our findings therefore include 14 new potentially interacting cytoplasmic 16 proteins.

A

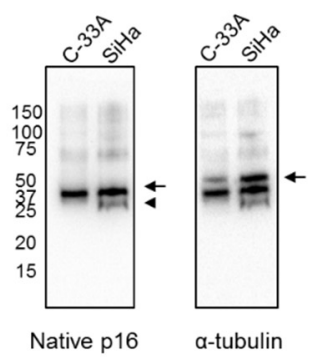

C

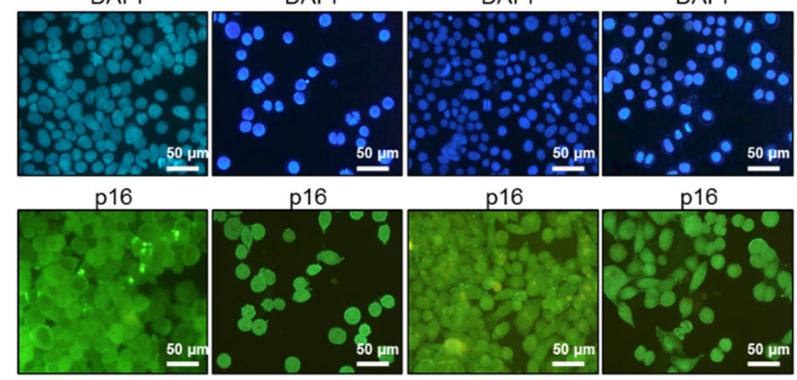

B
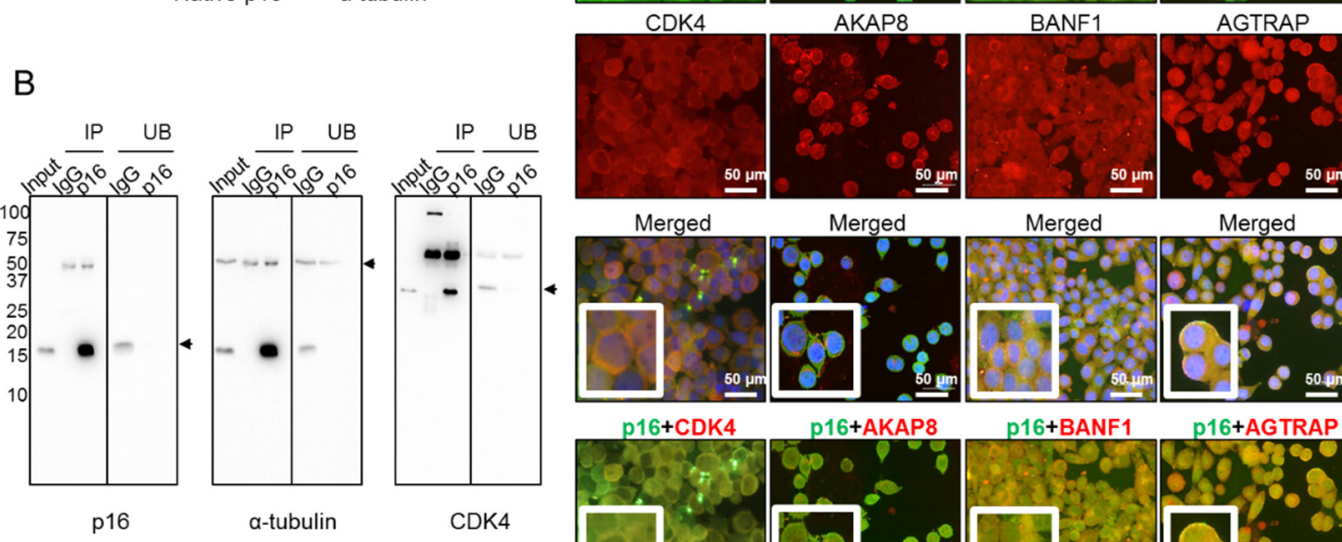

Merged Merged

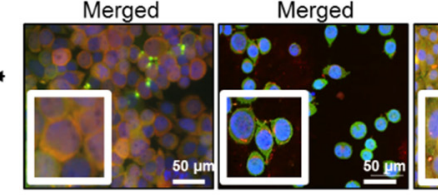

Merged

Merged

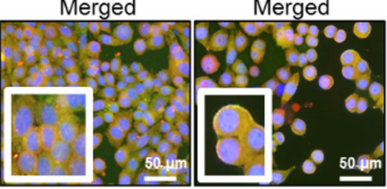

$16+$ CDK4

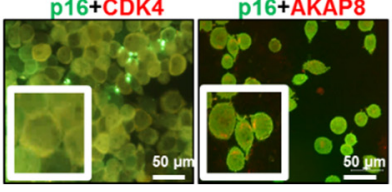

p16+BANF

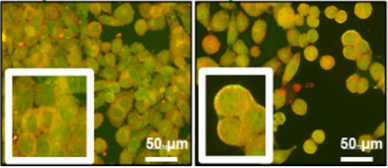

Figure 4. Cytoplasmic p16 interactors in SiHa cells. (A) Native form of p16 protein was examined in both $\mathrm{C}-33 \mathrm{~A}$ and $\mathrm{SiHa}$ cell lines by western blot under non-denaturing conditions. Arrows point to the proteins of interest, while the arrowhead indicates a different 3D conformation of native p16 in SiHa, as compared with C-33A. $\alpha$-tubulin was used as a loading control. (B) Exclusively cytoplasmic p16 was immunoprecipitated from SiHa cells, and efficiency was checked by western blot. Immunoprecipitated (IP) and unbound (UB) fractions upon incubation with IgG and anti-p16 antibodies are shown. $\alpha$-tubulin was used as a loading control. Immunoprecipitation of p16 interactors was checked by incubating the same membrane with an anti-CDK4 antibody, a very well-known p16-interacting protein. The arrows indicate the proteins of interest. (C) Colocalization in the cytoplasm of SiHa cells of p16 (in green) and four interactors (in red), identified by liquid chromatography-tandem mass spectrometry (LC-MS/MS), was revealed by double immunofluorescence. Images were acquired at $400 \times$ magnification. 
Table 2. Cytoplasmic p16 interactome in SiHa cells. 16 proteins were simultaneously identified in two independent experiments through in-solution- and in-gel-digested extracts from immunoprecipitated p16 in the SiHa cell line (false-discovery rate (FDR) < 0.01).

\begin{tabular}{|c|c|c|c|}
\hline Protein Name & UniProt ID & Gene Name & Brief Description \\
\hline Cyclin-dependent kinase 4 & P11802 & CDK4 & $\begin{array}{l}\text { Ser/Thr-kinase which phosphorylates and inhibits members of the } \mathrm{Rb} \text { protein family to allow dissociation of E2F, } \\
\text { which is responsible for the progression through the } \mathrm{G}_{1} \text { phase of the cell cycle. }\end{array}$ \\
\hline $\begin{array}{l}\text { Complement component } 1 \mathrm{Q} \text { subcomponent-binding } \\
\text { protein, mitochondrial }\end{array}$ & Q07021 & $C 1 Q B P$ & $\begin{array}{l}\text { Involved in inflammation and infection processes, ribosome biogenesis, protein synthesis in mitochondria, } \\
\text { regulation of apoptosis, transcriptional regulation and pre-mRNA splicing. It is required for the nuclear } \\
\text { translocation of splicing factor U2AF1L4. Involved in regulation of CDKN2A-mediated apoptosis. Stabilizes } \\
\text { mitochondrial CDKN2A isoform smARF. }\end{array}$ \\
\hline Type-1 angiotensin II receptor-associated protein & Q6RW13 & AGTRAP & Negative regulator of type-1 angiotensin II receptor-mediated signaling. \\
\hline A-kinase anchor protein 8 & $\mathrm{O} 43823$ & AKAP8 & $\begin{array}{l}\text { Anchoring protein which mediates the subcellular compartmentation of PKA type II. May help to deliver cyclin } \\
\text { D/E to CDK4 to facilitate cell cycle progression. Involved in nuclear retention of RPS6KA1 upon ERK activation } \\
\text { thus inducing cell proliferation. May be involved in recruitment of active CASP3 to the nucleus in apoptotic cells } \\
\text { May act as a carrier protein of GJA1 for its transport to the nucleus. }\end{array}$ \\
\hline THO complex subunit 4 & E9PB61 & ALYREF & Export adapter involved in nuclear export of spliced and unspliced mRNA. \\
\hline Barrier-to-autointegration factor & O75531 & BANF1 & $\begin{array}{l}\text { Plays fundamental roles in nuclear assembly, chromatin organization, gene expression and gonad development. } \\
\text { Promotes integration of viral DNA into the host chromosome. }\end{array}$ \\
\hline ATP-dependent RNA helicase DDX24 & Q9GZR7 & DDX24 & ATP-dependent RNA helicase. \\
\hline $40 \mathrm{~S}$ ribosomal protein $\mathrm{S} 30$ & E9PR30 & FAU & Ubiquitin-like and ribosomal protein S30 fusion. \\
\hline Heterogeneous nuclear ribonucleoprotein U-like protein 1 & Q9BUJ2 & HNRNPUL1 & Represses transcription driven by several virus and cellular promoters. \\
\hline Polyadenylate-binding protein 2 & Q86U42 & PABPN1 & $\begin{array}{l}\text { Involved in the } 3^{\prime} \text {-end formation of mRNA precursors by the addition of a poly(A) tail and various stages of mRNA } \\
\text { metabolism including nucleocytoplasmic trafficking. }\end{array}$ \\
\hline cGMP-specific 3',5'-cyclic phosphodiesterase & O76074 & PDE5A & Hydrolysis of cGMP to 5'-GMP. \\
\hline Pregnancy zone protein & P20742 & $P Z P$ & Proteinase inhibition. \\
\hline U5 small nuclear ribonucleoprotein $200 \mathrm{kDa}$ helicase & O75643 & SNRNP200 & RNA helicase essential for pre-mRNA splicing. \\
\hline Serine/arginine repetitive matrix protein 1 & Q8IYB3 & SRRM1 & Part of pre- and post-splicing multiprotein mRNP complexes involved in numerous pre-mRNA processing events. \\
\hline Testis-specific Y-encoded-like protein 2 & Q9H2G4 & TSPYL2 & May inhibit cell proliferation by inducing p53-dependent $C D K N 1 A$ expression. \\
\hline ATPase WRNIP1 & Q96S55 & WRNIP1 & Modulator of DNA polymerase delta-mediated DNA synthesis. \\
\hline
\end{tabular}




\subsection{Colocalization of Cytoplasmic p16 and Interactors in SiHa Cells}

Some of the cytoplasmic p16 interactors identified by LC-MS/MS were selected for further examination by double immunofluorescence because of their involvement in other carcinogenic processes [23-29]. As seen in Figure 4C, we found that CDK4, the A-kinase anchor protein 8 (AKAP8), the barrier to autointegration factor (BANF1), and the type-1 angiotensin II receptor-associated protein (AGTRAP) colocalized with p16 in the cytoplasm of SiHa cells, confirming that these proteins interact with cytoplasmic p16 in SiHa cells.

\section{Discussion}

Although p16 overexpression is a potential biomarker for CC clinical management $[5,17,18]$, there is a lack of consensus [5,19] and standard guidelines [2] concerning its routine use. Similarly, the biological significance of the paradoxical activation of this tumor-suppressor protein in CC is not yet well understood.

We confirmed p16 overexpression in our series of 78 cervical tumors, as extensively described $[3,14,16,21]$, since strong p16 expression is a proven useful surrogate biomarker for tumors with transcriptionally active HR-HPV [5]. Importantly, we found that p16 expression-and especially the cytoplasmic/nuclear p16 ratio-significantly distinguished HSIL from SCCC. Our findings are therefore evidence of the usefulness of p16 as a diagnostic biomarker between HSIL and SCCC, as previously proposed $[18,19]$. In fact, it has facilitated inter-observer agreement and then has improved the accuracy of traditional diagnostic methods based on histological observation in lower grade lesions $[4-6,21,30]$.

Notably, a high level of p16 expression was significantly associated with longer survival in our SCCC series, irrespective of other clinical parameters such as age, stage and vascular invasion. Although some reports have associated p16 overexpression with poor prognosis [3,14], our results are consistent with those of a meta-analysis involving 1633 CC patients [5]. It is thought that HR-HPV-related tumors are less genetically altered, and therefore tend to respond better to therapy and to have improved outcome $[5,15]$. Here, we noticed that $6 \%$ of SCCCs had null or low p16 levels. Although our sample number is limited, we have observed the same small proportion of p16 negative SCCC patients than a recent report where such patients negative for global p16, which represented only $4 \%$ of CC cases, had significantly worse OS [31].

It has been suggested that the lack of a standardized cut-off point for $\mathrm{p} 16$ overexpression could have masked its true clinical value [5]. However, as it is difficult to establish a cut-off value in subjectively evaluated immunohistochemical staining, the novelty of our study relies on the relevance of p16 subcellular location. To date, p16 expression pattern remains controversial, because there is no fundamental justification yet as to whether cytoplasmic/nuclear or only nuclear staining should be taken as positive [15]. As other authors have found [5,32], there was no association between p16 expression or location and pathological variables in our study, but we did find that the lack of nuclear p16 allowed SCCC to acquire aggressive features both in tumors and in vitro. This interesting finding goes some way to explaining the paradoxical p16 overexpression in SCCC. It is thought that retinoblastoma $(\mathrm{Rb})$ protein inhibition by HPV E7 protein triggers a negative feedback that leads to $\mathrm{p} 16$ overexpression, in a failed attempt to stop cell proliferation $[3,5,15,17]$. Our results could explain this failure, since, although overexpressed, p16 would not be able to fulfil any anti-tumor function in the cytoplasm. Cytoplasmic levels of some typical nuclear cell cycle regulators, such as p16, p27 and PTEN, have been described and associated with tumor progression in uterine leiomyosarcomas, astrocytomas, gastrointestinal stromal tumors and breast and colorectal cancer [15,17]. However, cytoplasmic p16 has been subtly examined in CC, found to be not significantly associated with the histological grade of the lesion [17] and associated with a borderline-significantly worse two-year PFS in HSIL patients ( $p=$ 0.049) [33].

Cytoplasmic p16 has only recently been evaluated, having been considered a background factor in many studies, and so its significance is due for reinterpretation [15]. Some authors have characterized 
p16 expression in CC cell lines and found very opposite results in comparison with ours: exclusively cytoplasmic p16 in C-33A cells and nuclear/cytoplasmic p16 in SiHa and HeLa cells [18]. Nevertheless, it is important to mention that they described p16 subcellular location solely in cell lines, which are just models of disease with many limitations that can influence protein levels and location. In contrast, our conclusions are supported by observations in tissues. Based on this, our study demonstrates that cytoplasmic p16 is not an artefact but has important biological and clinical implications. It has been hypothesized that the binding of p16 to other cytoplasmic proteins could form large molecules that are unable to pass through the nuclear membrane pores. Among these proteins, AE1 is thought to be present in gastric and colon cancer cells [15]; while PCNA, MCM6, $\alpha / \beta / \gamma$-actin and $\alpha / \beta$-tubulin, among others, have been observed in a lymphoblastoid cell line [34]. Although it is conceivable that cytoplasmic p16 interactors are cellular-context-dependent, CDK4 has been proposed as a strong candidate for sequestering p16 in the cytoplasm [15]. In fact, the interaction between p16 and CDK4 has already been demonstrated via co-immunoprecipitation in SiHa cells [35]. Accordingly, we also found binding and colocalization of p16 and CDK4 in SiHa cell cytoplasm, which strengthened the validity of our results. We also detected another p16 interactor already reported in the BioGRID repository, the complement component $1 \mathrm{Q}$ subcomponent-binding protein (C1QBP), which has been described as associating with the CDKN2A product to mediate apoptosis [36]. Apart from these, 14 new interactors of cytoplasmic p16 were also identified here. Importantly, we confirmed the colocalization of p16 with a protein subset previously involved in carcinogenesis with a specific role in nuclear shuttling. For instance, BANF1 has been reported to be involved in colony formation, migration and invasion in CC [37] and in the development of hepatocellular [23] and esophageal squamous cell [24] carcinomas and gastric cancer [26]. It is also known to interact with a protein which prevents nuclear accumulation of other proteins, such as $\beta$-catenin [38]. Another novel p16 interactor identified here, AKAP8, dynamically interacts with other proteins during cell cycle progression [39] and appears to play an important role in promoting lung [27], ovarian [28] and rectal [29] cancers. Moreover, it helps deliver cyclin D/E to CDK4 [40] and interacts with a kinase which phosphorylates p27 to prevent its translocation to the nucleus [41]. Finally, we identified AGTRAP, a HIF1 $\alpha$ direct target related to reduced PFS in melanoma [25] and to tumor growth and angiogenesis in Lewis lung carcinoma [42].

Further evaluation is warranted to confirm these observations in larger cohorts of patients, and to answer many questions that have been raised. For instance, whether p16 sequestration in the cytoplasm per se is the reason for the failure of its tumor-suppressor function or whether it involves more complex mechanisms is still to be determined. Since p16 overexpression has been observed at the invasive front of endometrial, colorectal and basal cell carcinoma, it has been proposed that cytoplasmic p16 is involved in the dissociation of focal adhesions, and then, related to cell invasion [15], lymphangiogenesis and lymphatic metastasis [5].

The potential therapeutic value of p16 is also to be elucidated. On the one hand, depletion of p16 has been shown to promote chemo- and radioresistance in HeLa cells [32]. On the other hand, it has been suggested that p16 could be a therapeutic target in CC, since its knockdown inhibits cell proliferation, migration and invasion in SiHa and HeLa cell lines [43] and sensitizes SiHa cells to cisplatin [35]. However, given the importance of its tumor-suppressor properties in other cell types, it is not clear how p16 inhibition would affect organism homeostasis. Here, we draw attention to a potential therapeutic use for $\mathrm{p} 16$ that works not by targeting it directly, but by inhibiting the proteins which sequester it in the cytoplasm. This strategy would be expected to release and translocate p16 to the nucleus in order to exert its tumor-suppressor function.

Recently, novel proteins, such as PDL1 [44], survivin [45] and SIRT1 [46], have become of interest as diagnostic or prognostic biomarkers in cervical malignancies. Undoubtedly, these findings are very important for SCCC clinical management, but their implementation would have economic consequences. In contrast, our results imply that it is only necessary to evaluate the p16 immunohistochemical pattern accurately—and since this is already routinely performed—it would not incur any additional cost. 


\section{Materials and Methods}

\subsection{Patient Samples}

We analyzed a series of 78 formalin-fixed, paraffin-embedded samples from women diagnosed with HSIL $(n=29)$ and SCCC $(n=49)$. All patients were diagnosed between 1995 and 2015 in the Pathology Department of the Complejo Hospitalario de Navarra (Pamplona, Spain), Hospital Universitari de Bellvitge, (L'Hospitalet de Llobregat, Spain), Complejo Asistencial Universitario (León, Spain), and Hospital Universitari Arnau de Vilanova (Lleida, Spain). Clinical characteristics of SCCC patients are summarized in Table S3. No clinical follow-up was available for HSIL patients, since they were all successfully cured by surgery. All tumors were surgically removed and staged according to their size, histological grade and lymph node involvement. All cases were ensured to harbor at least $70 \%$ tumor cells. None of the patients had received radiotherapy or chemotherapy before surgery. The study was approved by the Navarre Ethics Committee for Clinical Research (PI_2018/75) on September 30th 2019, procedures were in accordance with the Helsinki declaration, and informed consent was obtained according to the current Spanish legislation.

\subsection{Immunohistochemistry}

Sections (4- $\mu \mathrm{m}$ thick) of 29 HSILs and 49 SCCCs were placed on slides and deparaffinized. After performing antigen retrieval at $37^{\circ} \mathrm{C}$ for $30 \mathrm{~min}$ with the cell conditioning 1 buffer (catalog number 950-124) at $\mathrm{pH} 8.4$, samples were incubated with the anti-p16 antibody (catalog number 805-4713, clone E6H4) [31] at $1 \mu \mathrm{g} / \mathrm{mL}$ for $28 \mathrm{~min}$ at $37^{\circ} \mathrm{C}$ in a Benchmark $\mathrm{XT}^{\circledR}$ Ventana immunostainer (all reagents and equipment from Roche, Basel, Switzerland). The pattern and intensity of expression were evaluated blind by two independent observers (T.Z. and E.M.-S.), and ascribed to one of four categories: 0, no expression; 1, weak expression; 2, moderate expression; and 3, strong expression. Images were acquired with a Leica DM4000B microscope (Leica, Wetzlar, Germany) and the NIS Elements v4.30 program (Nikon Instruments, Amsterdam, Netherlands).

\subsection{Cell Lines}

Two human SCCC cell lines were used in this study, C-33A (an HPV-negative carcinoma) and SiHa (an HPV16-positive SCCC), both of which were purchased from the American Type Cell Collection (ATCC, Rockville, MD, USA). Additionally, the HeLa cell line (HPV18-positive cervical adenocarcinoma) was also obtained from the ATCC. They were all grown in DMEM supplemented with $10 \%$ fetal bovine serum (FBS) and 1\% penicillin/streptomycin (all from Life Technologies, Carlsbad, CA, USA), at $37^{\circ} \mathrm{C}$ in a humidified atmosphere with $5 \% \mathrm{CO}_{2}$. Experiments were performed with Mycoplasma-free and recently authenticated cell lines at low passage.

\subsection{Western Blot}

p16 expression levels were checked in both cytoplasmic and nuclear fractions in three CC cell lines by western blot. Briefly, for subcellular fractionation, C-33A, SiHa and HeLa cells were grown to $70-80 \%$ confluence and lysed with a phosphate-buffered saline (PBS)-based buffer containing 1\% NP-40 (Thermo Fisher Scientific, Waltham, MA, USA) and protease inhibitors (Roche, Basel, Switzerland). Cells were then scraped and centrifuged at $13,000 \mathrm{rpm}$ for $1 \mathrm{~min}$ at $4{ }^{\circ} \mathrm{C}$. Cytoplasmic proteins in the supernatant were collected, while pellets were resuspended in $50 \mu \mathrm{L}$ of lysis buffer (7M urea, 2M thiourea and $50 \mathrm{mM}$ DTT), incubated on ice for $30 \mathrm{~min}$ and sonicated for two cycles of 20 s each in a Vibra-Cell ${ }^{\mathrm{TM}} 75185$ ultrasonic liquid processor (Bioblock Scientific, Illkirch, France). Finally, samples were centrifuged at $20,000 \times g$ for $20 \mathrm{~min}$ at $15{ }^{\circ} \mathrm{C}$, and nuclear proteins were collected from the supernatant. Protein concentrations were quantified using the Protein DC kit (Bio-Rad, Hercules, CA, USA) in an Epoch plate reader (BioTek, Winooski, VT, USA), following the manufacturers' recommendations. For western blot, $60 \mu \mathrm{g}$ of proteins were resolved by SDS-PAGE in a $15 \%$ polyacrylamide gel and transferred onto a nitrocellulose membrane (Bio-Rad, Hercules, CA, 
USA). The membrane was blocked with $5 \%$ non-fat milk and incubated with the anti-p16 antibody (805-4713, Roche, Basel, Switzerland) at $250 \mathrm{ng} / \mathrm{mL}$ overnight and at $4{ }^{\circ} \mathrm{C}$. Then, it was incubated with the secondary anti-mouse antibody (Bio-Rad, Hercules, CA, USA) at 1:2000 for $1 \mathrm{~h}$ at room temperature. The signal was detected with the SuperSignal West Pico Chemiluminescent Substrate kit (Thermo Fisher Scientific, Waltham, MA, USA) in a ChemiDoc imaging system (Bio-Rad, Hercules, CA, USA) using ImageLab v5.2 software. The GAPDH (CB1001 from Calbiochem, Burlington, MA, USA) and Histone H3 (ab17684 from Abcam, Cambridge, UK) antibodies were employed as loading controls for the cytoplasmic and nuclear fractions, respectively. Finally, the intensity of bands was quantitated by densitometric analysis using the ImageJ v1.50i program.

\subsection{Cell Proliferation and Invasion}

To evaluate the proliferative ability of CC cell lines, C-33A, SiHa and HeLa cells were seeded $(1 \times$ $10^{4}$ cells/well) into $400 \mu \mathrm{L}$ of medium in an E-plate L8 device (iCELLigence system, ACEA Biosciences, San Diego, CA, USA), after measuring the background in $100 \mu \mathrm{L}$ of medium. Two replicates for each condition were analyzed. Cell attachment, spreading and proliferation were monitored by real-time cell analysis for 7 days, on the basis of changes in cell-sensor impedance, as previously described [47]. To assess the invasive capability of CC cell lines, cells were starved overnight. Next day, extracellular matrix layer was prepared by adding $40 \mu \mathrm{L}$ of Matrigel ${ }^{\circledR}$ (BD Biosciences, Franklin Lake, NJ, USA) into Transwell ${ }^{\circledR}$ inserts with 8- $\mu \mathrm{m}$-pore membranes (Sarstedt, Nümbrecht, Germany). After gelling for $15-30$ min at $37^{\circ} \mathrm{C}$, starved cells were seeded $\left(1.25 \times 10^{5}\right.$ cells/insert) on the gel layer in FBS-free medium, and the insert was placed in a well with FBS-containing medium. Cells were allowed to digest and penetrate the Matrigel ${ }^{\circledR}$ layer as far as the membrane for $72 \mathrm{~h}$. Then, non-invading cells and the gel layer were removed, and membranes were fixed and stained with a crystal violet solution containing paraformaldehyde (Sigma-Aldrich, St Louis, MO, USA). Images were taken with a Leica DMi1 microscope and the Leica Application Suite v4.12 program (Leica, Wetzlar, Germany).

\section{6. p16 Native form Identification}

In order to explore whether p16 subcellular location depended on the 3D conformation of the p16+interactors complex, the p16 native form was interrogated in SCCC cell lines. To do this, C-33A and $\mathrm{SiHa}$ cells were scraped and centrifuged at $4000 \mathrm{rpm}$ for $1 \mathrm{~min}$. Pellets were resuspended in $50-200 \mu \mathrm{L}$ of non-denaturing lysis buffer ( $20 \mathrm{mM}$ Tris- $\mathrm{HCl}, 137 \mathrm{mM} \mathrm{NaCl}, 2 \mathrm{mM}$ EDTA and protease inhibitors) and incubated on ice for $5 \mathrm{~min}$. After centrifuging at $8000 \times \mathrm{g}$ for $10 \mathrm{~min}$ at $4{ }^{\circ} \mathrm{C}$, proteins contained in the supernatants were quantified, and $50 \mu \mathrm{g}$ of native protein Were subjected to PAGE on an $8 \%$ polyacrylamide gel under non-denaturing conditions. Transfer, blocking, incubation with antibodies and revealing were performed as described above.

\section{7. p16 Immunoprecipitation}

To identify cytoplasmic p16 interactors, p16 was first immunoprecipitated from SiHa cells. Briefly, cells were grown to 70-80\% confluence, lysed with a home-made IP buffer $(50 \mathrm{mM}$ Tris- $\mathrm{HCl}, 150 \mathrm{mM}$ $\mathrm{NaCl}, 1 \mathrm{mM}$ EDTA, 1\% Triton and protease inhibitors) and centrifuged at maximum speed for $10 \mathrm{~min}$. Proteins contained in the supernatants were quantified as described above, and three aliquots were separated: $50 \mu \mathrm{g}$ Were denatured and stored to check the input by western blot; $5 \mathrm{mg}$ Were incubated with $10 \mu \mathrm{g}$ of anti-p16 antibody (ab108349, Abcam, Cambridge, UK); and $5 \mathrm{mg}$ Were incubated with an irrelevant antibody (rabbit IgG, 10500C, Thermo Fisher Scientific, Waltham, MA, USA). Incubations were performed overnight at $4{ }^{\circ} \mathrm{C}$ in a rotating wheel. The next day, $30 \mu \mathrm{L}$ of protein A/G-coated magnetic beads (Thermo Fisher Scientific, Waltham, MA, USA) Were added to each sample and incubated for $2 \mathrm{~h}$ at room temperature to allow them to bind to the antigen-antibody complex. Extracts were sequentially washed three times with IP buffer using a magnetic stand. Finally, $30 \mu \mathrm{L}$ of IP buffer and $10 \mu \mathrm{L}$ of Laemmli buffer $4 \times$ Were added, and samples were heated at $95^{\circ} \mathrm{C}$ for $5 \mathrm{~min}$ to denature and unbind the magnetic beads. A magnetic stand was used to remove magnetic beads. 
A small $5-\mu \mathrm{L}$ fraction of the eluted extract was separated to check immunoprecipitation efficiency by western blot, using the $\alpha$-tubulin antibody (T-6074 from Sigma-Aldrich, St Louis, MO, USA) as a loading control, while $15 \mu \mathrm{L}$ Were subjected to mass spectrometry.

\subsection{Mass Spectrometry and Bioinformatic Analysis}

SiHa protein extracts incubated with the anti-p16 and the IgG antibodies were analyzed by LC-MS/MS using two parallel strategies: i) extracts were subjected to SDS-PAGE in a Criterion ${ }^{\mathrm{TM}} \mathrm{TGX}$ Stain-Free ${ }^{\mathrm{TM}}$ protein gel (Bio-Rad, Hercules, CA, USA), and bands were individually excised from the gel and then digested; ii) extracts were directly digested in solution. In both cases, protein extracts were trypsin-digested and cleaned with ZipTip. Resulting samples were examined in a Triple-TOF 5600+ (Sciex, Framingham, MA, USA) coupled to a NanoLC Ultra 1D Plus nanochromatograph (Eksigent, Dublin, CA, USA), as previously described [48]. MS/MS data were acquired using Analyst 1.7.1 (Sciex, Framingham, MA, USA) and spectra files were processed with Protein Pilot Software v.5.0 (Sciex, Framingham, MA, USA) using the Paragon ${ }^{\mathrm{TM}}$ algorithm for database searching, Progroup ${ }^{\mathrm{TM}}$ for data grouping, and searched against the concatenated target-decoy UniProt human proteome reference database (Proteome ID: UP000005640, 73045 proteins, April 2018) plus Human papillomavirus type 16 database (Proteome ID: UP000009251, 9 proteins, April 2018). The FDR was estimated using a non-linear fitting method and the results displayed were those for a global FDR of $1 \%$ or better. Proteins unequivocally detected in both workflows in the extract with the anti-p16 antibody but not present in the anti-IgG sample and with an FDR $<1 \%$ were considered to be potential p16 interactors. Their biological functions were interrogated using the UniprotKB/Swiss-Prot (https://www.uniprot.org/) database. Additionally, the p16 interactors identified here were compared with those available in the interaction repository BioGRID (Biological General Repository for Interaction Datasets, v3.5.173, https://thebiogrid.org/) [49].

\subsection{Immunofluorescence}

In order to confirm p16 expression pattern in cultured SCCC cells and to assess colocalization of cytoplasmic p16 and its potential interactors, cells were seeded on coverslips and allowed to attach overnight. Cells were then fixed with $4 \%$ paraformaldehyde, blocked with 5\% FBS in PBS at room temperature for $1 \mathrm{~h}$, and incubated at $4{ }^{\circ} \mathrm{C}$ overnight with primary antibodies: anti-p16 (805-4713, Roche, Basel, Switzerland) at $250 \mathrm{ng} / \mathrm{mL}$, and anti-CDK4 (ab108357, Abcam, Cambridge, UK), anti-BANF1 (CSB-PA002550LA01HU), anti-AKAP8 (STJ91533) or anti-AGTRAP (CSB-PA744194LA01HU) (all from Antibodyplus, Inc., Brookline, MA, USA), at 1:150. All samples were simultaneously incubated with AlexaFluor 488 anti-mouse and AlexaFluor 568 anti-rabbit (1:200) (Life Technologies, Carlsbad, CA, USA) at room temperature for $1 \mathrm{~h}$. Finally, samples were mounted on slides with DAPI to counterstain nuclei. Images were acquired with a Leica DM4000B microscope (Leica, Wetzlar, Germany), using the NIS Elements v4.30 program (Nikon Instruments, Amsterdam, Netherlands), and excitation/emission wavelengths of 340-380/425 nm, 450-490/525 nm, and 560/40-645/75 nm for blue, green and red, respectively.

\subsection{Statistical Analysis}

Demographic, clinical and pathological data were summarized as frequencies (and percentages) and means (and ranges) \pm standard error of the mean, as appropriate. All statistical analyses were carried out using IBM SPSS Statistics v25. Immunohistochemical expression levels in HSIL and SCCC samples, as well as differences in cell line proliferation, were compared using the Mann-Whitney test. Association between clinical variables and p16 expression or location was tested using a $\chi^{2}$ contingency test. Kaplan-Meier plots and log-rank tests were used to examine the association of p16 expression and location, age, stage and vascular invasion with PFS and OS in SCCC patients. A multivariate Cox regression model was fitted to test the independent contribution of each variable to the patient's 
outcome after adjusting. Hazard ratios and $95 \%$ confidence intervals were used to estimate the effect of each variable on the outcome.

\section{Conclusions}

In conclusion, we have gained further insight into the paradox of p16 overexpression in CC: it is expressed at high levels, but not located where it would act as a tumor-suppressor protein. We propose then that exploring 16 subcellular location can provide more useful information regarding anti-tumor activity than $\mathrm{p} 16$ overall expression examination. In particular, cytoplasmic p16, which is sequestered by novel proteins identified here for the first time, is more frequently observed in SCCC than HSIL and is associated with a worse outcome in SCCC. Therefore, the ratio of cytoplasmic to nuclear p16 and the absence of nuclear p16 could be independent biomarkers for SCCC diagnosis and prognosis, respectively.

Supplementary Materials: Supplementary materials can be found at http://www.mdpi.com/1422-0067/21/6/2125/ s1.

Author Contributions: Conceptualization, E.M.-S.; methodology, E.M.-S.; software, J.F.-I., E.S. and E.M.-S.; validation, E.M.-S.; formal analysis, J.F.-I., E.S. and E.M.-S.; investigation, S.M., T.Z., K.A., M.J.D.d.C. and E.M.-S.; resources, J.F.-I., E.S., R.G., D.G.-S., A.V., J.S.-S., X.M.-G.; data curation, J.F.-I., E.S. and E.M.-S.; writing—original draft preparation, E.M.-S.; writing-review and editing, J.F.-I., E.S. and E.M.-S.; visualization, E.M.-S.; supervision, E.M.-S.; project administration, E.M.-S.; funding acquisition, D.G.-S. All authors have read and agreed to the published version of the manuscript.

Funding: This research was funded by the Health Department of the Navarre Government (Grant number 21/11), the Navarre Breast Cancer Patients' Association (SARAY) and the "Proof of concept project on proteomic research" from Proteored (Grant number ProteoRed-0000029). The Proteomics Unit of Navarrabiomed is a member of Proteored, PRB3-ISCIII, and is supported by Grant PT17/0019/009, of the PE I + D + I 2013-2016 funded by ISCIII and ERDF. S.M. was a recipient of a predoctoral grant from the Public University of Navarre. E.M.-S. was a recipient of a fellowship from the Spanish Ministry of Science, Innovation and Universities (PTA2015-11895-I).

Acknowledgments: We thank the staff of the Biobank in Navarrabiomed and the Pathology Department of the Complejo Hospitalario de Navarra (both in Pamplona, Spain) for their excellent technical assistance with the histological and immunohistochemical techniques.

Conflicts of Interest: The authors declare no conflict of interest. The funders had no role in the design of the study, the collection, analyses or interpretation of data, the writing of the manuscript or in the decision to publish the results.

\section{Abbreviations}

AGTRAP Type-1 angiotensin II receptor-associated protein

AKAP8 A-kinase anchor protein 8

ATCC American Type Cell Collection

BANF1 Barrier to autointegration factor

BioGRID Biological General Repository for Interaction Datasets

C1QBP Complement component $1 \mathrm{Q}$ subcomponent-binding protein

CC Cervical cancer

CDK4 Cyclin-dependent kinase 4

CI Confidence interval

FBS Fetal bovine serum

FDR False-discovery rate

HR-HPV High-risk human papillomavirus

HSIL High-grade squamous intraepithelial lesion

LC-MS/MS Liquid chromatography-tandem mass spectrometry

OS Overall survival

p16 Cyclin-dependent kinase inhibitor 2A protein

PBS Phosphate-buffered saline

PFS Progression-free survival

$\mathrm{Rb} \quad$ Retinoblastoma protein

SCCC Squamous cell carcinoma of the cervix 


\section{References}

1. World Health Organization. Available online: https://www.who.int/cancer/prevention/diagnosis-screening/ cervical-cancer/en/ (accessed on 15 July 2019).

2. Marth, C.; Landoni, F.; Mahner, S.; McCormack, M.; Gonzalez-Martin, A.; Colombo, N.; Committee, E.G. Cervical cancer: ESMO Clinical Practice Guidelines for diagnosis, treatment and follow-up. Ann. Oncol. 2017, 28, iv72-iv83. [CrossRef] [PubMed]

3. Saavedra, K.P.; Brebi, P.M.; Roa, J.C. Epigenetic alterations in preneoplastic and neoplastic lesions of the cervix. Clin. Epigenet. 2012, 4, 13. [CrossRef] [PubMed]

4. Reuschenbach, M.; Wentzensen, N.; Dijkstra, M.G.; von Knebel Doeberitz, M.; Arbyn, M. p16INK4a immunohistochemistry in cervical biopsy specimens: A systematic review and meta-analysis of the interobserver agreement. Am. J. Clin. Pathol. 2014, 142, 767-772. [CrossRef]

5. Lin, J.; Albers, A.E.; Qin, J.; Kaufmann, A.M. Prognostic significance of overexpressed p16INK4a in patients with cervical cancer: A meta-analysis. PLoS ONE 2014, 9, e106384. [CrossRef] [PubMed]

6. Sun, H.; Shen, K.; Cao, D. Progress in immunocytochemical staining for cervical cancer screening. Cancer Manag. Res. 2019, 11, 1817-1827. [CrossRef] [PubMed]

7. Kocken, M.; Helmerhorst, T.J.; Berkhof, J.; Louwers, J.A.; Nobbenhuis, M.A.; Bais, A.G.; Hogewoning, C.J.; Zaal, A.; Verheijen, R.H.; Snijders, P.J.; et al. Risk of recurrent high-grade cervical intraepithelial neoplasia after successful treatment: A long-term multi-cohort study. Lancet Oncol. 2011, 12, 441-450. [CrossRef]

8. Coates, A.S.; Winer, E.P.; Goldhirsch, A.; Gelber, R.D.; Gnant, M.; Piccart-Gebhart, M.; Thürlimann, B.; Senn, H.J.; Members, P. Tailoring therapies-improving the management of early breast cancer: St Gallen international expert consensus on the primary therapy of early breast cancer 2015. Ann. Oncol. 2015, 26, 1533-1546. [CrossRef]

9. Bernicker, E.H.; Allen, T.C.; Cagle, P.T. Update on emerging biomarkers in lung cancer. J. Thorac. Dis. 2019, 11, S81-S88. [CrossRef]

10. Wick, W.; Weller, M.; van den Bent, M.; Sanson, M.; Weiler, M.; von Deimling, A.; Plass, C.; Hegi, M.; Platten, M.; Reifenberger, G. MGMT testing-the challenges for biomarker-based glioma treatment. Nat. Rev. Neurol. 2014, 10, 372-385. [CrossRef]

11. Harbeck, N.; Sotlar, K.; Wuerstlein, R.; Doisneau-Sixou, S. Molecular and protein markers for clinical decision making in breast cancer: Today and tomorrow. Cancer Treat. Rev. 2014, 40, 434-444. [CrossRef]

12. Lindeman, N.I.; Cagle, P.T.; Aisner, D.L.; Arcila, M.E.; Beasley, M.B.; Bernicker, E.H.; Colasacco, C.; Dacic, S.; Hirsch, F.R.; Kerr, K.; et al. Updated Molecular Testing Guideline for the Selection of Lung Cancer Patients for Treatment With Targeted Tyrosine Kinase Inhibitors: Guideline From the College of American Pathologists, the International Association for the Study of Lung Cancer, and the Association for Molecular Pathology. Arch. Pathol. Lab. Med. 2018, 142, 321-346. [CrossRef] [PubMed]

13. Sepulveda, A.R.; Hamilton, S.R.; Allegra, C.J.; Grody, W.; Cushman-Vokoun, A.M.; Funkhouser, W.K.; Kopetz, S.E.; Lieu, C.; Lindor, N.M.; Minsky, B.D.; et al. Molecular Biomarkers for the Evaluation of Colorectal Cancer: Guideline From the American Society for Clinical Pathology, College of American Pathologists, Association for Molecular Pathology, and the American Society of Clinical Oncology. J. Clin. Oncol. 2017, 35, 1453-1486. [CrossRef] [PubMed]

14. Cardoso, M.F.S.; Castelletti, C.H.M.; Lima-Filho, J.L.; Martins, D.B.G.; Teixeira, J.A.C. Putative biomarkers for cervical cancer: SNVs, methylation and expression profiles. Mutat. Res. 2017, 773, 161-173. [CrossRef] [PubMed]

15. Romagosa, C.; Simonetti, S.; López-Vicente, L.; Mazo, A.; Lleonart, M.E.; Castellvi, J.; Ramon y Cajal, S. p16(Ink4a) overexpression in cancer: A tumor suppressor gene associated with senescence and high-grade tumors. Oncogene 2011, 30, 2087-2097. [CrossRef]

16. Sarma, U.; Biswas, I.; Das, A.; Das, G.C.; Saikia, C.; Sarma, B. p16INK4a expression in cervical lesions correlates with histologic grading-A tertiary level medical facility based retrospective study. Asian Pac. J. Cancer Prev. 2017, 18, 2643-2647. [CrossRef]

17. Conesa-Zamora, P.; Doménech-Peris, A.; Orantes-Casado, F.J.; Ortiz-Reina, S.; Sahuquillo-Frías, L.; Acosta-Ortega, J.; García-Solano, J.; Pérez-Guillermo, M. Effect of human papillomavirus on cell cycle-related proteins p16, Ki-67, Cyclin D1, p53, and ProEx C in precursor lesions of cervical carcinoma: A tissue microarray study. Am. J. Clin. Pathol. 2009, 132, 378-390. [CrossRef] 
18. Vázquez-Vega, S.; Sánchez-Suárez, L.P.; Contreras-Paredes, A.; Castellanos-Juárez, E.; Peñarroja-Flores, R.; Lizano-Soberón, M.; Andrade-Cruz, R.; García-Carrancá, A.; Benítez-Bribiesca, L. Nuclear co-expression of p14ARF and p16INK4A in uterine cervical cancer-derived cell lines containing HPV. Cancer Biomark. 2010, 8, 341-350. [CrossRef]

19. Pandey, A.; Chandra, S.; Nautiyal, R.; Shrivastav, V. Expression of p16 ${ }^{\mathrm{INK} 4 \mathrm{~A}}$ and human papillomavirus 16 with associated risk factors in cervical premalignant and malignant lesions. South Asian J. Cancer 2018, 7, 236-239. [CrossRef]

20. Volgareva, G.; Zavalishina, L.; Andreeva, Y.; Frank, G.; Krutikova, E.; Golovina, D.; Bliev, A.; Spitkovsky, D.; Ermilova, V.; Kisseljov, F. Protein p16 as a marker of dysplastic and neoplastic alterations in cervical epithelial cells. BMC Cancer 2004, 4, 58. [CrossRef]

21. Wu, M.Z.; Wang, S.; Zheng, M.; Tian, L.X.; Wu, X.; Guo, K.J.; Zhang, Y.I.; Wu, G.P. The diagnostic utility of p16 immunostaining in differentiating cancer and HSIL from LSIL and benign in cervical cells. Cell Transpl. 2019, 28, 195-200. [CrossRef]

22. Kurman, R.J.; Carcangiu, M.L.; Herrington, C.S.; Young, R.H. Tumours of the uterine cervix. In WHO Classification of Tumours of Female Reproductive Organs, 4th ed.; IARC Press: Lyon, France, 2014; Volume 6, pp. 169-207.

23. Shen, Q.; Eun, J.W.; Lee, K.; Kim, H.S.; Yang, H.D.; Kim, S.Y.; Lee, E.K.; Kim, T.; Kang, K.; Kim, S.; et al. Barrier to autointegration factor 1, procollagen-lysine, 2-oxoglutarate 5-dioxygenase 3, and splicing factor 3b subunit 4 as early-stage cancer decision markers and drivers of hepatocellular carcinoma. Hepatology 2018, 67, 1360-1377. [CrossRef]

24. Li, J.; Wang, T.; Pei, L.; Jing, J.; Hu, W.; Sun, T.; Liu, H. Expression of VRK1 and the downstream gene BANF1 in esophageal cancer. Biomed. Pharmacother. 2017, 89, 1086-1091. [CrossRef]

25. Loftus, S.K.; Baxter, L.L.; Cronin, J.C.; Fufa, T.D.; Pavan, W.J.; Program, N.C.S. Hypoxia-induced HIF1 $\alpha$ targets in melanocytes reveal a molecular profile associated with poor melanoma prognosis. Pigment Cell Melanoma Res. 2017, 30, 339-352. [CrossRef]

26. Li, J.; Hu, B.; Fang, L.; Gao, Y.; Shi, S.; He, H.; Liu, X.; Yuan, C. Barrier-to-autointegration factor 1: A novel biomarker for gastric cancer. Oncol. Lett. 2018, 16, 6488-6494. [CrossRef]

27. Chen, Y.D.; Chen, X.X.; Shen, L.N.; Liang, F.C.; Ding, Y.; Yu, X.Y.; Xue, M.Q.; Zhang, Y.X. Expression of A-kinase anchor protein 95, cyclin E2, and connexin 43 in lung cancer tissue, clinical significance of their expression, and their expression correlation. Zhonghua Lao Dong Wei Sheng Zhi Ye Bing Za Zhi 2012, 30, 725-729.

28. Liu, W.; Hua, S.; Dai, Y.; Yuan, Y.; Yang, J.; Deng, J.; Huo, Y.; Chen, X.; Teng, B.; Yu, X.; et al. Roles of Cx43 and AKAP95 in ovarian cancer tissues in G1/S phase. Int. J. Clin. Exp. Pathol. 2015, 8, 14315-14324.

29. Qi, F.; Yuan, Y.; Zhi, X.; Huang, Q.; Chen, Y.; Zhuang, W.; Zhang, D.; Teng, B.; Kong, X.; Zhang, Y. Synergistic effects of AKAP95, Cyclin D1, Cyclin E1, and Cx43 in the development of rectal cancer. Int. J. Clin. Exp. Pathol. 2015, 8, 1666-1673.

30. Van Zummeren, M.; Leeman, A.; Kremer, W.W.; Bleeker, M.C.G.; Jenkins, D.; van de Sandt, M.; Heideman, D.A.M.; Steenbergen, R.; Snijders, P.J.F.; Quint, W.G.V.; et al. Three-tiered score for Ki-67 and $\mathrm{p} 16^{\mathrm{INK} 4 \mathrm{~A}}$ improves accuracy and reproducibility of grading CIN lesions. J. Clin. Pathol. 2018, 71, 981-988. [CrossRef]

31. Nicolas, I.; Saco, A.; Barnadas, E.; Marimon, L.; Rakislova, N.; Fuste, P.; Rovirosa, A.; Gaba, L.; Bunesch, L.; Gil-Ibanez, B.; et al. Prognostic implications of genotyping and p16 immunostaining in HPV-positive tumors of the uterine cervix. Mod. Pathol. 2020, 33, 128-137. [CrossRef]

32. Fu, H.C.; Chuang, I.C.; Yang, Y.C.; Chuang, P.C.; Lin, H.; Ou, Y.C.; Chang Chien, C.C.; Huang, H.S.; Kang, H.Y. Low P16INK4A expression associated with high expression of cancer stem cell markers predicts poor prognosis in cervical cancer after radiotherapy. Int. J. Mol. Sci. 2018, 19, 2541. [CrossRef]

33. Andrade, C.E.; Scapulatempo-Neto, C.; Longatto-Filho, A.; Vieira, M.A.; Tsunoda, A.T.; Da Silva, I.D.; Fregnani, J.H. Prognostic scores after surgical treatment for cervical intraepithelial neoplasia: A proposed model and possible implications for post-operative follow-up. Acta Obstet. Gynecol. Scand. 2014, 93, 941-948. [CrossRef]

34. Souza-Rodrígues, E.; Estanyol, J.M.; Friedrich-Heineken, E.; Olmedo, E.; Vera, J.; Canela, N.; Brun, S.; Agell, N.; Hübscher, U.; Bachs, O.; et al. Proteomic analysis of p16ink4a-binding proteins. Proteomics 2007, 7, 4102-4111. [CrossRef] 
35. Li, Y.; Xiao, S.; Dan, L.; Xue, M. P16 ${ }^{\mathrm{INK} 4 \mathrm{~A}}$ is required for cisplatin resistance in cervical carcinoma SiHa cells. Oncol. Lett. 2015, 9, 1104-1108. [CrossRef]

36. Itahana, K.; Clegg, H.V.; Zhang, Y. ARF in the mitochondria: The last frontier? Cell Cycle 2008, 7, 3641-3646. [CrossRef]

37. Mao, L.; Zhang, Y.; Mo, W.; Yu, Y.; Lu, H. BANF1 is downregulated by IRF1-regulated microRNA-203 in cervical cancer. PLoS ONE 2015, 10, e0117035. [CrossRef]

38. Markiewicz, E.; Tilgner, K.; Barker, N.; van de Wetering, M.; Clevers, H.; Dorobek, M.; Hausmanowa-Petrusewicz, I.; Ramaekers, F.C.; Broers, J.L.; Blankesteijn, W.M.; et al. The inner nuclear membrane protein emerin regulates beta-catenin activity by restricting its accumulation in the nucleus. EMBO J. 2006, 25, 3275-3285. [CrossRef]

39. Chen, X.; Kong, X.; Zhuang, W.; Teng, B.; Yu, X.; Hua, S.; Wang, S.; Liang, F.; Ma, D.; Zhang, S.; et al. Dynamic changes in protein interaction between AKAP95 and Cx43 during cell cycle progression of A549 cells. Sci. Rep. 2016, 6, 21224. [CrossRef]

40. Arsenijevic, T.; Degraef, C.; Dumont, J.E.; Roger, P.P.; Pirson, I. A novel partner for D-type cyclins: Protein kinase A-anchoring protein AKAP95. Biochem. J. 2004, 378, 673-679. [CrossRef]

41. Larrea, M.D.; Hong, F.; Wander, S.A.; da Silva, T.G.; Helfman, D.; Lannigan, D.; Smith, J.A.; Slingerland, J.M. RSK1 drives p27Kip1 phosphorylation at T198 to promote RhoA inhibition and increase cell motility. Proc. Natl. Acad. Sci. USA 2009, 106, 9268-9273. [CrossRef]

42. Imai, N.; Hashimoto, T.; Kihara, M.; Yoshida, S.; Kawana, I.; Yazawa, T.; Kitamura, H.; Umemura, S. Roles for host and tumor angiotensin II type 1 receptor in tumor growth and tumor-associated angiogenesis. Lab. Investig. 2007, 87, 189-198. [CrossRef]

43. Zhang, C.Y.; Bao, W.; Wang, L.H. Downregulation of p16(ink4a) inhibits cell proliferation and induces G1 cell cycle arrest in cervical cancer cells. Int. J. Mol. Med. 2014, 33, 1577-1585. [CrossRef]

44. Nicol, A.F.; de Andrade, C.V.; Gomes, S.C.; Brusadelli, M.G.; Lodin, H.M.; Wells, S.I.; Nuovo, G.J. The distribution of novel biomarkers in carcinoma-in-situ, microinvasive, and squamous cell carcinoma of the uterine cervix. Ann. Diagn. Pathol. 2019, 38, 115-122. [CrossRef]

45. Liu, H.Q.; Wang, Y.H.; Wang, L.L.; Hao, M. P16INK4A and survivin: Diagnostic and prognostic markers in cervical intraepithelial neoplasia and cervical squamous cell carcinoma. Exp. Mol. Pathol. 2015, 99, 44-49. [CrossRef]

46. Velez-Perez, A.; Wang, X.I.; Li, M.; Zhang, S. SIRT1 overexpression in cervical squamous intraepithelial lesions and invasive squamous cell carcinoma. Hum. Pathol. 2017, 59, 102-107. [CrossRef]

47. Martín-Sánchez, E.; Mendaza, S.; Ulazia-Garmendia, A.; Monreal-Santesteban, I.; Blanco-Luquin, I.; Córdoba, A.; Vicente-García, F.; Pérez-Janices, N.; Escors, D.; Megías, D.; et al. CHL1 hypermethylation as a potential biomarker of poor prognosis in breast cancer. Oncotarget 2017, 8, 15789-15801. [CrossRef]

48. Lachén-Montes, M.; González-Morales, A.; Zelaya, M.V.; Pérez-Valderrama, E.; Ausín, K.; Ferrer, I.; Fernández-Irigoyen, J.; Santamaría, E. Olfactory bulb neuroproteomics reveals a chronological perturbation of survival routes and a disruption of prohibitin complex during Alzheimer's disease progression. Sci. Rep. 2017, 7, 9115. [CrossRef]

49. Oughtred, R.; Stark, C.; Breitkreutz, B.J.; Rust, J.; Boucher, L.; Chang, C.; Kolas, N.; O’Donnell, L.; Leung, G.; McAdam, R.; et al. The BioGRID interaction database: 2019 update. Nucleic Acids Res. 2019, 47, D529-D541. [CrossRef]

(C) 2020 by the authors. Licensee MDPI, Basel, Switzerland. This article is an open access article distributed under the terms and conditions of the Creative Commons Attribution (CC BY) license (http://creativecommons.org/licenses/by/4.0/). 